\title{
Sterol 26-Hydroxylase, Mitochondrial
}

National Cancer Institute

\section{Source}

National Cancer Institute. Sterol 26-Hydroxylase, Mitochondrial. NCI Thesaurus. Code C104151.

Sterol 26-hydroxylase, mitochondrial (531 aa, $\sim 60 \mathrm{kDa}$ ) is encoded by the human CYP27A1 gene. This protein is involved in cholesterol homeostasis and bile synthesis. 